\title{
JUDEUS NO BRASIL: explorando os dados censitários"
}

\author{
René Daniel Decol
}

\section{Introdução}

Embora tenha crescido o número de trabalhos sobre a presença judaica no Brasil, ainda falta muito para que tenhamos um amplo panorama histórico. A história da imigração judaica ainda não foi mapeada com a mesma abrangência de outros grupos, como italianos e japoneses, talvez porque envolva dificuldades únicas - afinal, ao contrário da italiana ou japonesa, a imigração judaica partiu de dezenas de países diferentes (Grün, 1999). Para reconstruí-la é necessário compreender o contexto em que judeus viviam em regiões e situações tão diversas como a Europa Central no período entre as duas guerras mundiais e o Oriente Médio depois do aparecimento do Estado de Israel.

Por outro lado, devido também a suas características únicas, judeus formam um dos únicos grupos imigrantes sistematicamente pesquisados pelos censos demográficos brasileiros a partir de 1940.

\footnotetext{
Este artigo resume alguns tópicos desenvolvidos em minha tese de doutorado, Imigrações urbanas para o Brasil: o caso dos judeus, defendida no Instituto de Filosofia e Ciências Humanas (IFCH) da Unicamp, em 1999, sob a orientação de Daniel Hogan. Agradeço os comentários dos pareceristas anônimos da RBCS.
}

Isto se deve à existência da categoria "judeus" na pergunta sobre religião. Diferentemente de muitos países do mundo, o censo brasileiro traz uma pergunta sobre religião, o que nos permite traçar um amplo panorama das transformações religiosas ocorridas no Brasil nos últimos 50 anos (Decol, 1999). No caso específico dos judeus, a existência de informação censitária desde 1940 é uma vantagem interessante para o pesquisador interessado em resgatar a sua história.

O objetivo deste artigo é investigar algumas características sociodemográficas deste grupo, utilizando os dados censitários colhidos pelo IBGE nos censos decenais realizados entre 1940 e 1991. A questão da identidade judaica é assunto amplo demais para ser aqui discutido a fundo. Para a finalidade deste artigo é importante mencionar que os dados obtidos pelos censos demográficos são de natureza auto-identificatória: os entrevistados são convidados a responder qual a religião de cada um dos membros do seu domicílio. Embora a definição de quem é judeu ou não possa ganhar diferentes enfoques, na maior parte dos estudos quantitativos a única definição operacionalmente viável é justamente a autodefinição (Schmelz e DellaPergola, 1992, p. 486n). 
As dificuldades envolvendo a definição de quem é judeu, para fins de pesquisa social empírica, foram exaustivamente analisadas por Schmelz e DellaPergola (1992, p. 486):

Em muitos aspectos, judeus partilham das dificuldades enfrentadas quando se tenta definir, identificar e enumerar minorias nas sociedades contemporâneas. As dificuldades são ampliadas pelas características únicas deste grupo, onde se misturam componentes religiosos, étnicos, culturais e históricos, bem como pela sua dispersão geográfica e estrutura socioeconômica muito particular. Nas sociedades contemporâneas que experimentam processos intensos de secularização, aculturação e interação social, as linhas demarcatórias que separam diferentes grupos religiosos, étnicos e culturais não são mais rígida e claramente demarcadas, como acontecia no passado. Múltiplas bases de identificação entre indivíduos e grupos podem coexistir. Como a identificação não é regulada legalmente, indivíduos podem mudar suas preferências durante seu ciclo vital. Indivíduos de origem judaica podem vivenciar diferentes níveis de vinculação ao judaísmo ou à comunidade judaica, e podem resolver cortar os respectivos elos, adotando ou não outra identidade. Estas mudanças atitudinais são reversíveis: pessoas que negam seu vínculo com o judaísmo podem mudar de idéia mais tarde. Alguns, ainda, podem admitir ou negar a identidade judaica dependendo das circunstâncias. Outro elemento deste quadro é a freqüência crescente de casamentos mistos. Alguns casais preferem unificar a família, um dos cônjuges adotando a religião do outro; outros preferem manter as diferentes identidades religiosas. Filhos de casais mistos, por sua vez, estão sujeitos a serem expostos às diferentes tradições de seus pais, a partir das quais sua própria identidade será moldada.

Para contornar as dificuldades impostas pela definição fluida e voluntarista de quem é judeu, os autores desenvolveram um quadro referencial onde definem três conceitos diferentes de população judaica: nuclear (aqueles que se definem como judeus quando perguntados, por exemplo, em um levantamento censitário); estendida (a população nuclear mais aqueles que, embora de origem judaica, não se definem atualmente como tais); e finalmente, ampliada (a população estendida mais os membros não-judeus de suas famílias, tais como cônjuges e filhos em casamentos mistos). De um ponto de vista operacional, os dados censitários se referem apenas à população nuclear e se referem àqueles que se definem como judeus por religião (já que a pergunta é formulada nos seguintes termos: "qual é a religião de cada um dos membros do domicílio?”). Outras definições, mais amplas, provavelmente nos levariam a números diferentes, abarcando outras definições. É o caso, por exemplo, dos descendentes de judeus que, no contexto de uma sociedade em processo intenso de secularização como a brasileira, em número cada vez maior se dizem sem religião. É possível que muitos se definiriam como judeus por outras características (sociais, étnicas, culturais ou históricas) se a pergunta tivesse outra natureza. ${ }^{1}$ A experiência dos levantamentos censitários sobre judeus em outros países, como o Canadá (Millman, 1983), mostra que o grupo que se define como judeu por religião forma um núcleo central ao redor do qual gravita uma população maior e que envolve judeus por outro tipo de definição, além de familiares não-judeus. Os dados censitários, portanto, embora não abarquem outras definições possíveis da população judaica, jogam alguma luz sobre um componente importante - seu núcleo central.

Os dados são importantes não apenas para a comunidade judaica brasileira mas também para pesquisadores do ciclo da imigração internacional para o Brasil. Afinal, oferecem a rara oportunidade da rastrear a evolução de um grupo de imigrantes ao longo de sua trajetória de assimilação na sociedade brasileira. Dada a condição singular dos judeus, o grupo carrega um "marcador": a religião judaica, que pode ser rastreada ao longo de sucessivas gerações pela pergunta do censo. Uma pergunta sobre país de nascimento, para pessoas nãonaturais do Brasil, permite identificar imigrantes pelo país de origem - mas isto é possível apenas para a geração dos que imigraram. Para seus filhos, já nascidos no Brasil, a informação sobre a origem 
se perde. Portanto, não é possível utilizar dados censitários para outros grupos étnicos por mais de uma geração. Judeus são uma notável exceção porque o "marcador" religião é uma característica, em geral, transmitida ao longo de gerações.

Portanto, além de todas as incertezas inerentes a qualquer tentativa de medição quantitativa em ciências sociais (King, Keohane e Verba, 1994), os dados censitários ainda trazem um nível adicional de incerteza, devido às complexidades envolvidas na definição de quem é judeu. Como judeus eram discriminados em boa parte de seus países de origem (inclusive legalmente), esta incerteza era menor no passado mas cresce à medida que seus filhos se integram na sociedade brasileira.

Outra incerteza adicional está relacionada com a metodologia censitária, já que a pergunta sobre religião provém do questionário da amostra, aplicado apenas a um subconjunto da população. Esta incerteza, decorrente do erro amostral, incide apenas nos levantamentos a partir de 1960, quando foi introduzido o procedimento - nos censos de 1940 e 1950 a pergunta sobre religião era feita no questionário universal. $\mathrm{O}$ erro amostral, por outro lado, deve ser maior para 1991 do que para 1980, já que a amostra utilizada em 1991 foi menor do que a de 1980. Outras incertezas podem ainda ter afetado os dados mais recentes: como argumenta Grün (1999, p. 363n), evangélicos podem ter se declarado judeus, principalmente a partir de 1991, quando a presença deste grupo se torna mais significativa.

Estes diferentes níveis de incerteza, que incidem de forma diferenciada ao longo da série histórica, alertam sobre a cautela que se faz necessária na análise. Ainda assim, os dados são relevantes. Como lembram os metodólogos, um tópico importante em ciências sociais merece ser estudado mesmo que a qualidade dos dados seja limitada. As conclusões assim obtidas podem ter seu alcance limitado pela qualidade dos dados e devem ser relativizadas; mas, uma vez que o pesquisador reporte o nível de incerteza envolvido, é possível obter ganhos significativos em conhecimento sobre o tópico em questão (King, Keohane e Verba, 1994, p. 6).

\section{Revisão da literatura}

Entre os estudos que têm sido publicados sobre judeus no Brasil, nota-se uma preocupação em definir os principais parâmetros quantitativos, preocupação esta fundamental quando se analisa um grupo pequeno e com características tão peculiares. Sendo um grupo cuja chegada no Brasil é mais recente que a dos imigrantes "clássicos" (alemães, italianos e japoneses, por exemplo), é natural que haja um interesse em determinar o seu tamanho e suas características demográficas e socioeconômicas. Devido ao foco específico deste artigo, a revisão da literatura a seguir se refere apenas aos estudos relevantes para um enfoque demográfico.

Rattner (1972) é um pioneiro neste tipo de estudo, tendo coordenado uma pesquisa realizada por instituições comunitárias em fins dos anos 60, no município de São Paulo. Utilizando seus resultados, este autor publicou em 1977 um amplo perfil quantitativo, com foco em aspectos culturais e sociológicos. Deve-se a Rattner, ainda, a divulgação entre nós de textos clássicos sobre a imigração judaica, principalmente Lestschinsky (1961) e Engelman (1961), publicados em sua antologia Nos caminhos da diáspora (Rattner, 1972).

Lesser (1995) trouxe uma contribuição importante aos estudos de cunho demográfico ao focalizar um período específico, aquele em que a chamada "questão judaica" emergiu no país. Com sua pesquisa, Lesser supriu lacunas importantes na historiografia, localizando algumas das principais correntes migratórias que marcaram a chegada do grupo. Autores como Grün (1999) têm explorado interpretações históricas de diversos aspectos do perfil social e cultural da comunidade, baseados em dados quantitativos históricos e naqueles revelados por Rattner. Outros autores, como Blay (1997), têm se concentrado em correntes específicas dentro do mosaico étnico judaico.

Poucos, no entanto, têm usado os dados provenientes da pergunta sobre religião dos censos demográficos decenais. A rigor, apenas dois pesquisadores israelenses, Schmelz e DellaPergola (1985), detiveram-se sobre os dados censitários brasileiros ao elaborar um panorama demográfico sobre os judeus da América Latina. O interesse pelo 
conjunto da comunidade latino-americana, no entanto, impediu que os autores se aprofundassem mais detidamente no caso brasileiro. Além disso, os últimos dados disponíveis quando da publicação do seu artigo eram os do censo de 1980.

Muito importante, do ponto de vista metodológico, é o artigo de Schmelz (1981) onde estão delineados os principais conceitos necessários a uma análise demográfica de qualquer comunidade judaica (ou, de resto, de qualquer grupo religioso), seja em Israel ou na diáspora. Neste artigo seminal, Schmelz mostra que, com exceção dos Estados Unidos, na maioria dos países da diáspora os judeus já enfrentavam, por volta do início da década de 1980, taxas negativas de crescimento populacional.

Em geral, são significativas as observações de Levine (1995) de que, em grande parte, a literatura sobre judeus ainda guarda um tom de celebração, típico dos primeiros escritos sobre grupos imigrantes, onde predominam tentativas de mostrar que importantes personagens da história eram judeus, ou descendentes de cristãos-novos. Levine lembra também que, enquanto muito se fala sobre judeus famosos, pouco sabemos sobre o grosso da comunidade:

Sabemos muito sobre empresários de sucesso [...], escritores e artistas de origem judaica [...] Por outro lado, a literatura nos diz pouco sobre judeus brasileiros menos proeminentes [...] A maior parte do que foi publicado procura fazer uma crônica da história de sinagogas, clubes e instituições comunitárias, passando ao largo da vida de pessoas comuns, e sem colocar a vida de judeus brasileiros no contexto mais amplo da sociedade brasileira, como se judeus vivessem em um vácuo. [...] Não sabemos praticamente nada, por exemplo, sobre os cerca de $30 \%$ dos judeus brasileiros que não estão engajados na indústria, nos negócios ou nas profissões liberais e que, portanto, não pertencem à classe média afluente. (Levine, 1995)

É sensível também a falta de informações básicas sobre a comunidade do ponto de vista demográfico: afinal, quantos são os judeus brasileiros, de onde vieram, em que época e onde se instalaram? Onde vivem hoje, como estão distribuídos no espaço geográ- fico, onde estão concentrados? A ausência deste mapeamento inicial prejudica tentativas de se fazer um mapeamento mais abrangente da comunidade. Parte desta ausência pode ser explicada pelas dificuldades inerentes ao tema, já apontadas.

Uma maneira de se suprir estas lacunas é utilizando dados dos censos demográficos, que, evidentemente, trazem informações não apenas de judeus proeminentes. Embora poucos estudos tenham usado esta fonte de dados, "judeus" é, como vimos, uma das categorias investigadas pela declaração de religião dos censos do IBGE desde $1940 .^{2}$ Há dados censitários publicados, portanto, cobrindo todo o período que vai de 1940 a 1991, com exceção de 1970, quando o grupo foi incluído em uma categoria genérica e residual, "outros".

Além disso, com o avanço recente das ferramentas de informática, dados censitários relativos aos levantamentos de 1970 em diante estão agora à disposição dos pesquisadores em discos laser, o que permite uma grande flexibilidade na obtenção dos mais diversos tipos de cruzamentos entre variáveis. Assim, é possível extrair um grande conjunto de dados demográficos e socioeconômicos relativos à subpopulação de religião judaica no âmbito dos últimos dois censos, o de 1980 e o de 1991. No presente artigo, procurei fazer uma análise de alguns aspectos sociodemográficos da comunidade judaica brasileira utilizando dados publicados dos censos de 1940 em diante e processamentos especiais dos censos de 1980 e 1991. Uma análise mais abrangente, incluindo aspectos socioeconômicos, pode ser encontrada na minha tese de doutorado (Decol, 1999). Além de atualizar a série histórica, é a primeira vez que se utilizam processamentos especiais para se estudar uma minoria religiosa brasileira.

Antes da análise propriamente dita, vale a pena discutir por que estes dados existem - ou seja, as razões pelas quais judeus passaram a ser pesquisados pelos censos demográficos brasileiros. Afinal, o censo é fundamentalmente um instrumento de coleta de informações que possam nortear políticas públicas. Mas o censo é também um espelho da sociedade: muitas das suas questões provêm de interesses políticos existentes no momento em que o levantamento é organizado (Ro- 
bey, 1984; Anderson, 1988). Em diversos momentos da história e em vários países, censos foram utilizados também para obter informações sobre minorias indesejáveis, muitas vezes com o objetivo de subsidiar políticas restritivas. Isto aconteceu com judeus, por exemplo, na Rússia czarista do século XIX (Rowland, 1986). E com grande sofisticação organizacional e tecnológica no censo da Alemanha nazista de 1939 (Seltzer, 1998; Black, 2001). Até que ponto o namoro de Getúlio Vargas com o nazismo era o pano de fundo para a existência de uma categoria independente para os judeus no censo brasileiro de 1940 é assunto aberto a discussões. Vale lembrar que Giorgio Mortara, demógrafo italiano de ascendência judaica que foi o diretor técnico do censo de 1940, conta em sua autobiografia que quando assumiu o cargo encontrou as perguntas já prontas (Mortara, 1985). Uma vez introduzida, a categoria acabou permanecendo nos questionários dos levantamentos seguintes, tradição que persiste até hoje. ${ }^{3}$

\section{Dados censitários sobre judeus: interesse político ou curiosidade sociológica?}

Como se sabe, a presença judaica no Brasil data do período colonial. Banidos da Península Ibérica a partir de fins do século $\mathrm{XV}$, judeus convertidos em cristãos-novos tiveram participação importante nos primórdios da formação da população brasileira. No entanto, não fizeram isso como judeus, com uma identidade religiosa, cultural e histórica distinta.

A presença judaica assumida como tal tem início apenas no século XIX, após a Constituição de 1824 ter instituído formalmente a liberdade religiosa no país. Como fenômeno de massa, no entanto, a imigração judaica começou depois do desenvolvimento da navegação a vapor e do estabelecimento de linhas comerciais entre a Europa e o Brasil, o que aconteceria só na segunda metade do século XIX (Moya, 1998). Mas o movimento ganharia volume significativo apenas na segunda metade da década de 1920, quando Estados Unidos e Argentina introduziram restrições à entrada de determinados grupos. O Brasil, que desde fins do século XIX se estabelecera como um importante destino da migração internacional, tornou-se uma alternativa natural. Sucessivamente, judeus provenientes do Império Russo, dos Bálcãs e da Europa Central passaram a chegar em números crescentes: calcula-se que, entre 1920 e o início da Segunda Guerra Mundial, mais de 50 mil judeus tenham aqui aportado (Lestschinsky, 1961; Wischnitzer, 1948).

Desde as últimas décadas do século XIX, o Brasil havia recebido alguns milhões de imigrantes europeus, vindos principalmente da Itália, Alemanha, Portugal, Espanha e Polônia. Embora, a princípio, a maior parte desta imigração fosse rural, começava a crescer a participação de fluxos com destino às cidades (Klein, 1999; Fausto, 1991). O grosso da imigração, no entanto, era rural. Calculase que $70 \%$ da imigração italiana tenha tido origem e destino rural (Alvim, 1998; Trento, 1989). Este seria o caso de $50 \%$ da imigração portuguesa (Klein, 1989). Mesmo com metade do seu contingente se dirigindo para destinos rurais, a imigração portuguesa é considerada a mais urbana de todas as migrações "clássicas” (Klein, 1989).

Neste contexto, alguns grupos, como judeus, sírios e libaneses, se diferenciavam por apresentar características singulares (Truzzi, 1997). Em primeiro lugar, o fato de serem mais urbanos. Esta característica é particularmente significativa no caso dos judeus. Os judeus se urbanizaram mais cedo do que a maioria dos grupos populacionais e de forma universal (Engelman, 1961; Lestschinsky, 1961). Já na Antiguidade apresentavam características peculiarmente urbanas (Baron, 1957) e, por circunstâncias históricas muito específicas, continuaram sendo um grupo essencialmente urbano ao longo de sua história. Claro que a própria definição do que é "urbano" variou consideravelmente ao longo deste período. De qualquer forma, pode-se afirmar que judeus estiveram quase sempre, e em grande maioria, no nível mais urbano possível em cada momento histórico.

$\mathrm{O}$ resultado disto foi sua marginalização durante o período feudal, quando o poder era baseado na posse da terra e o comércio, desprezado. Impedidos de terem acesso à terra, judeus foram mantidos à margem da economia senhorial, estigmatizados e legalmente discriminados. Com as revoluções comercial e industrial, judeus viram nas 
cidades em expansão uma oportunidade que se abria para escapar desta posição subalterna (Lestschinsky, 1961).

Quando começaram a chegar em números maiores ao Brasil, já na década de 20, o país iniciava sua transição para uma nação cada vez mais urbana e industrializada. Com uma vocação urbana bem mais acentuada que todos os outros grupos imigrantes, os judeus se dirigiram, em sua grande maioria, principalmente para três grandes centros urbanos: Rio de Janeiro, São Paulo e Porto Alegre. ${ }^{4}$

Uma vez instalados, os judeus começaram a atrair atenção, devido às suas características peculiares. Da concentração urbana decorria uma estrutura ocupacional singular, em que predominava o comércio e os pequenos empreendimentos domésticos. $^{5}$ Devido às suas diferenças, incluindo sua concentração residencial nos bairros centrais das cidades onde se fixaram, judeus eram mais "visíveis" do que outros grupos de imigrantes. Logo membros da elite católica que governava o país começariam a se alarmar: a população judaica estava crescendo rápido demais - ou pelo menos assim parecia.

A partir de 1937, com a ascensão do Estado Novo de Getúlio Vargas, começa a tomar corpo a versão brasileira da "questão judaica" (Tucci Carneiro, 1988; Lesser, 1995). ${ }^{6}$ Logo começaria uma discussão pública se era conveniente ou não a presença de judeus no Brasil. Parte da discussão envolvia uma questão política: Getúlio, como acontecia na Alemanha nazista, procurava identificar judeus e comunistas. Parte da discussão envolvia uma questão demográfica: segundo alguns, centenas de milhares de judeus já haviam entrado e se instalado no país. Se nada fosse feito, outros milhares, ou talvez até milhões, poderiam procurar refúgio em terras brasileiras.

A rigor, o tamanho exato da comunidade judaica não era conhecido nesta época. O Brasil não realizava um censo desde 1920. E mesmo este levantamento, que deixara muito a desejar em termos de qualidade, não trouxera uma questão sobre religião. As primeiras informações estatísticas confiáveis sobre a presença judaica no Brasil provêm do censo de 1940, cujos resultados só seriam conhecidos em 1943. Ainda assim, no auge do
Estado Novo, durante o debate sobre a "questão judaica”, alguns faziam estimativas altamente exageradas. "400 mil judeus vivem no Brasil; 150 mil entraram nos últimos seis meses", publicou no final de 1940 o Meio-Dia, jornal carioca financiado por alemães (Lesser, 1995, p. 231). Quando os dados censitários foram finalmente publicados, soube-se que a comunidade judaica tinha algo ao redor de 50 mil pessoas - cerca de oito vezes menos do que apregoava a manchete alarmista do Meio-Dia.

Durante o período em que a "questão judaica" era debatida publicamente começaram os trabalhos de preparação do censo de 1940. Provavelmente devido ao interesse pela questão, judeus foram enumerados em uma categoria independente da pergunta sobre religião. Note-se que a pergunta sobre religião já aparecera nos censos do Império, o que talvez possa ser atribuído ao interesse, na época, pela chegada dos primeiros imigrantes alemães de religião protestante e a conseqüente formação do primeiro núcleo populacional não-católico do país. E judeus já haviam sido tabulados separadamente em 1900, embora na época não passassem de algumas centenas. De forma que, quando o censo de 1940 investigou a presença de judeus, não havia aí nenhuma grande novidade na metodologia do censo. A novidade era, no entanto, que agora havia algumas dezenas de milhares deles no país.

Qualquer que tenha sido o contexto político no qual surgiu o interesse na enumeração em separado de pessoas de religião judaica, quando os resultados foram finalmente publicados o cenário já havia mudado: Getúlio Vargas abandonara sua simpatia pelo Eixo e se juntara aos aliados. A "questão judaica" desapareceu - ou pelo menos submergiu. Ao lado dos argumentos que faziam restrições à presença do grupo no Brasil, uma nova voz surgira no debate, argumentando que a presença judaica seria benéfica, porque traria capital, além de habilidades técnicas e comercias, coisas importantes para um país em pleno processo de modernização e industrialização (Lesser, 1995).

A persistência do grupo como categoria nos censos de 1950 em diante pode ser explicada, talvez, pelo interesse sociológico em uma minoria com características sociodemográficas muito espe- 
cíficas. Parece inegável, no entanto, que a introdução da categoria no censo de 1940 tenha se dado por razões políticas.

\section{A imigração judaica no contexto da imigração internacional para o Brasil}

Nos cem anos entre as décadas de 1870 e 1970, mais de 5 milhões de imigrantes chegaram ao Brasil (Bassanezi, 1996). A imigração em geral teve seu auge na última década de século XIX, tendo voltado a crescer nas primeiras décadas do século $\mathrm{XX}$ e nos anos 50. Comparada aos demais fluxos, a imigração judaica é relativamente recente nas terras brasileiras: judeus participaram muito pouco do primeiro e mais intenso fluxo imigratório, em que predominava o elemento rural.

Judeus começaram a imigrar com mais intensidade já nos anos 20, com a chegada de dezenas de milhares, provenientes sobretudo da Europa Central, do Leste, e da região dos Bálcãs. A emigração era freqüentemente apontada como solução para o problema das minorias na Europa do Centro-Leste (Mendelsohn, 1983). A Tabela 1 compara a imigração em geral para o Brasil com a judaica, mostrando a defasagem entre ambas.

Tabela 1

Brasil - Imigração Geral e Judaica, por Períodos, 1872-1972

\begin{tabular}{lrrrr}
\hline Período & \multicolumn{2}{c}{ Geral } & \multicolumn{2}{c}{ Judaica } \\
\hline $1872-1879$ & 176.337 & $3,3 \%$ & 500 & $0,5 \%$ \\
$1880-1889$ & 448.622 & $8,4 \%$ & 500 & $0,5 \%$ \\
$1890-1899$ & 1.198 .327 & $22,4 \%$ & 1.000 & $1,1 \%$ \\
$1900-1909$ & 622.407 & $11,6 \%$ & 5.000 & $5,4 \%$ \\
$1910-1919$ & 815.453 & $15,2 \%$ & 5.000 & $5,4 \%$ \\
$1920-1929$ & 846.647 & $15,8 \%$ & 30.316 & $32,5 \%$ \\
$1930-1939$ & 332.768 & $6,2 \%$ & 22.452 & $24,1 \%$ \\
$1940-1949$ & 114.085 & $2,1 \%$ & 8.512 & $9,1 \%$ \\
$1950-1959$ & 583.068 & $10,9 \%$ & 15.243 & $16,3 \%$ \\
$1960-1969$ & 197.587 & $3,7 \%$ & 4.258 & $4,6 \%$ \\
$1970-1972$ & 15.558 & $0,3 \%$ & 450 & $0,5 \%$ \\
Total $1872-1972$ & 5.350 .859 & $100,0 \%$ & 93.231 & $100,0 \%$ \\
\hline
\end{tabular}

Fontes: Para imigração geral, Bassanezi (1996, p. 8); para a judaica, estimativas do autor baseadas nos censos do IBGE, em Wischnitzer (1948, p. 293) e em Lestschinsky (1961, p. 1.554).
A partir dos anos 60, tanto a imigração geral como a judaica entrariam em declínio. Privada do que fora sua principal fonte de crescimento no passado, a população judaica teria de contar, daí em diante, apenas com seu próprio crescimento vegetativo para manter seu contingente demográfico. Como judeus provenientes da Europa formavam, em qualquer momento, a maioria da população judaica, o grupo como um todo teve suas características demográficas fortemente determinadas pelo componente shkenazi. ${ }^{7}$

Como outros grupos descendentes de europeus, judeus ashkenazis já apresentavam, desde as primeiras décadas do século, baixas taxas de natalidade. Atualmente, na maioria dos países da diáspora $^{8}$ onde se estabeleceram, suas taxas de fecundidade já estão abaixo do nível de reposição necessário para a reprodução intergeracional (Schmelz, 1981). Estimativas para os judeus brasileiros, baseadas nos dados dos censos, sugerem que já em 1980 o grupo apresentava taxas de fecundidade abaixo do nível de reposição. ${ }^{9}$

Como conseqüência, uma vez extinta a imigração, a partir dos anos 60, a comunidade como um todo apresentaria baixas taxas de crescimento, como mostra a Tabela 2.

Tabela 2

Brasil - População Judaica, de Acordo com os Censos

\begin{tabular}{lcrrcc}
\hline & 1940 & 1950 & 1960 & 1980 & 1991 \\
\hline Censos & 55.563 & 69.955 & 96.199 & 91.795 & 86.417 \\
Ajustada* $^{5} 56.000$ & 70.000 & 86.000 & 90.000 & 86.000 \\
\hline
\end{tabular}

\footnotetext{
* Ajustes propostos por Schmelz e DellaPergola, refletindo as incertezas em torno das informações censitárias.

Fontes: IBGE, Censos demográficos; Schmelz e DellaPergola (1985, p. 74).
}

Os dados mostram que, se a comunidade judaica cresceu significativamente nos anos 40 e 50 , este crescimento perdeu seu ímpeto em algum momento a partir dos anos 60. Em 1980 a comunidade teria experimentado seu auge, com cerca de 90 mil indivíduos, tendo entrado em declínio desde então. De fato, provavelmente pela primeira vez neste século, o tamanho da população judaica diminuiu entre 1980 e 1991: 86 mil pessoas se identificaram (ou foram iden- 
tificadas por membros do domicílio) como judeus em 1991 - quatro mil a menos do que os 90 mil de 1980.

Resultado do interesse crescente no país pelo tema das migrações, os censos de 1980 e 1991 perguntaram aos não-naturais, isto é, aos não nascidos no Brasil, seu país de nascimento; o de 1991 perguntou ainda a data de chegada no Brasil. Estas informações, quando cruzadas com a declaração de religião, permitem obter um quadro dos principais países de origem da imigração judaica. Naturalmente, estes "instantâneos" refletem também o efeito da mortalidade e da reemigração acumulada até a ocasião das pesquisas. $\mathrm{O}$ resultado deste cruzamento está na Tabela 3.

Tabela 3

Brasil - Pessoas de Religião Judaica, por País de Nascimento, nas Datas dos Censos de 1980 e 1991

\begin{tabular}{lrr}
\hline & 1980 & \multicolumn{1}{c}{1991} \\
\hline Total & $\mathbf{9 1 . 7 9 5}$ & $\mathbf{8 6 . 4 1 7}$ \\
Nascidos no Brasil & $\mathbf{6 2 . 9 0 3}$ & $\mathbf{6 7 . 1 3 1}$ \\
Fora do Brasil & $\mathbf{2 8 . 8 9 2}$ & $\mathbf{1 9 . 2 8 6}$ \\
Polônia & 7.684 & 4.219 \\
Romênia & 3.281 & 2.030 \\
Alemanha & 2.727 & 1.691 \\
Egito & 2.222 & 1.504 \\
Israel & 1.835 & 1.443 \\
URSS & 1.786 & 1.076 \\
Argentina & 1.459 & 1.340 \\
Líbano & 937 & 826 \\
Hungria & 893 & 487 \\
Itália & 536 & 337 \\
\hline
\end{tabular}

Fonte: IBGE, Censos demográficos de 1980 e 1991, tabulações especiais do autor.

Como vemos na Tabela 3, o contingente mais significativo veio da Europa do Centro-Leste (Polônia, Romênia e Hungria), seguido pelos da Europa Central (Alemanha) e do Leste (União Soviética). ${ }^{10}$ Um outro fluxo importante teve origem no Oriente Médio (Egito e Líbano). A presença nesta lista de Israel e Argentina, destinos tradicionais da imigração judaica, reflete a importância de fluxos circulares entre as diversas comunidades da diáspora. Vale ressaltar que o grupo mais significativo tanto em 1980 quanto em 1991 era o de nascidos na Polônia.

Houve decréscimo no número de nascidos, para cada um dos países de origem, entre 1980 e 1991, devido ao efeito acumulado da mortalidade num contexto de imigração pouco significativa. A intensidade do declínio depende da maior ou menor antiguidade dos fluxos. Para poloneses e outros da Europa, o declínio foi maior, pois chegaram ao Brasil ainda nas primeiras décadas do século. Já o declínio entre sefaradis ${ }^{11}$ nascidos no Egito e no Líbano foi menor porque esta migração é mais recente.

Enquanto as gerações mais antigas sofreram o impacto da mortalidade, membros das novas coortes, já nascidos no Brasil, são afetados cada vez mais pela assimilação, casamentos mistos (Sorj, 1997a) e secularização. Uma taxa alta de casamentos mistos aumenta a possibilidade de perdas atitudinais, isto é, o fluxo de pessoas formal ou informalmente se convertendo para outra religião ou, como ocorre cada vez mais freqüentemente no Brasil, para os "sem religião".

De fato, há indícios de que a secularização, pelo menos para certos setores da sociedade, seja um fenômeno em crescimento, afetando principalmente as religiões tradicionais (Wilson, 1985). Este processo é visível no aumento significativo da proporção de pessoas que se definem como "sem religião" nas entrevistas censitárias. ${ }^{12}$ As pessoas que assim se identificam cresceram de menos de $1 \%$ de todos os brasileiros em 1940 para quase 5\% em 1991. Este crescimento é ainda mais intenso nas principais regiões metropolitanas. No Rio de Janeiro, quase 14\% dos respondentes disseram não ter nenhuma filiação religiosa em 1991, um crescimento considerável sobre os $5 \%$ que havia assim se manifestado no censo anterior, como se vê na Tabela 4.

Tabela 4

Estado do Rio de Janeiro - Distribuição Relativa da População por Grupos Religiosos, 1940-1991

\begin{tabular}{lrrrrrr}
\hline & 1940 & 1950 & 1960 & 1970 & 1980 & 1991 \\
\hline Católicos & 91,7 & 89,1 & 88,8 & 86,1 & 80,9 & 67,3 \\
Sem religião & 0,4 & 1,3 & 1,3 & 2,1 & 4,9 & 13,9 \\
Evangélicos & 3,1 & 4,3 & 5,3 & 7,1 & 8,3 & 12,8 \\
Outros & 4,8 & 5,2 & 4,6 & 4,7 & 5,9 & 6,1 \\
Total & 100,0 & 100,0 & 100,0 & 100,0 & 100,0 & 100,0 \\
\hline
\end{tabular}

Fonte: IBGE, Censos demográficos de 1940 a 1991. 
O crescimento dos sem religião é um fenômeno ainda pouco estudado entre nós (Fonseca, 1998). A maior parte dos trabalhos sobre mudança religiosa tem enfocado o extremo oposto do espectro religioso, ou seja, a revitalização, expansão e multiplicação das religiões no país (Pierucci, 1998). Importante assinalar que as duas hipóteses não são excludentes: é possível que estejamos assistindo a uma polarização - isto é, setores da sociedade podem estar se tornando mais religiosos enquanto outros setores se tornam menos religiosos (Glenn, 1987). O censo, evidentemente, não é uma pesquisa específica sobre religião e não pode nos dar muitas respostas. Não temos informação, também, sobre o impacto diferencial da secularização em cada um dos diferentes grupos religiosos. ${ }^{13}$

\section{Distribuição espacial}

Quando o Brasil começou a atrair imigrantes da Europa, ainda era um país largamente rural, com a maior parte da sua população ocupada na agricultura. Por isso, a imigração internacional teve, pelo menos no início, um caráter rural. Com o tempo, foi se tornando mais urbana, à medida que avançava a urbanização não só no Brasil, como também nos países de origem. Há indícios, porém, de que pelo menos até a década de 20 ainda havia contingentes rurais significativos chegando ao país (Alvim, 1998). No balanço final, a imigração para o Brasil teve um resultado muito diferente daquele da imigração para os Estados Unidos. Enquanto lá predominou o elemento urbano (Bodnar, 1985), aqui predominou o elemento rural.

Neste contexto, os judeus que chegaram ao Brasil tiveram uma trajetória única. Como tinham pouca ou nenhuma experiência rural, dirigiram-se para as cidades bem mais cedo e de forma praticamente universal. $O$ resultado é que estiveram sempre mais concentrados nas cidades do que qualquer outro grupo imigrante, sem falar no conjunto da população brasileira como um todo. Como mostra a Tabela 5, por volta de 1940 , cerca de $74 \%$ do total de judeus residentes no Brasil já vivia em apenas três cidades: Porto Alegre, Rio de Janeiro e São Paulo. Em comparação, apenas $8 \%$ de todos os brasileiros viviam nestas cidades na mesma época.
Tabela 5

Brasil - População Judaica, por Municípios Selecionados

\begin{tabular}{lrrrr}
\hline Cidade & 1940 & \multicolumn{1}{c}{1950} & \multicolumn{1}{c}{1980} & \multicolumn{1}{c}{1991} \\
\hline São Paulo (1) & 17.219 & 22.808 & 41.308 & 38.843 \\
Rio de Janeiro (2) & 19.743 & 25.222 & 27.699 & 24.754 \\
Porto Alegre (3) & 4.331 & 5.557 & 7.051 & 7.118 \\
Subtotal (1+2+3) & 41.293 & 53.587 & 76.058 & 70.715 \\
BRASIL (4) & 55.563 & 69.955 & 91.795 & 86.416 \\
$(1+2+3) / 4$ & $74,3 \%$ & $76,6 \%$ & $82,9 \%$ & $81,8 \%$ \\
\hline
\end{tabular}

Fonte: IBGE, Censos demográficos de 1940, 1950, 1980 e 1991.

Como mostra ainda a Tabela 5, até pelo menos a década de 1950 o Rio de Janeiro era sede da maior colônia judaica no país. Sendo a capital, além de centro portuário e comercial, o Rio havia atraído a maior parte dos novos imigrantes, além dos que haviam se instalado inicialmente em outros portos de chegada: Belém, Recife e Salvador. Assim, a colônia do Rio chegou ao censo de 1950 com pouco mais de 25 mil pessoas. Mas, a partir de então, esta comunidade cresceria muito pouco, tendo atingido um tamanho máximo de quase 28 mil em 1980. Já em 1991, no entanto, as pessoas identificadas como de religião judaica somaram menos do que as 25 mil registradas em 1950.

Se a população judaica do Rio estagnou em algum ponto entre os anos 50 e 80 , São Paulo logo assumiria a liderança como principal concentração de pessoas de religião judaica no Brasil. Isto se deve, é claro, ao importante papel desempenhado por São Paulo no processo de industrialização no período posterior à Segunda Guerra Mundial. Liderando o processo, São Paulo torna-se a maior metrópole nacional do país, vindo a concentrar, em 1970, cerca de $15 \%$ da população urbana, 36\% do emprego industrial, e $43 \%$ do valor de transformação industrial do país (Araújo, 1992, p. 45).

Tamanho dinamismo gerava oportunidades não só na indústria, mas também no comércio e nos serviços, e a cidade converteu-se em um pólo de atração inevitável para as novas levas de imigrantes recém-chegados, incluindo duas novas importantes correntes de judeus: sobreviventes da Segunda Guerra Mundial e judeus expulsos dos países árabes depois da criação do Estado de Israel 
(Stillman, 1991). São Paulo chega a 1991, portanto, com mais de 41 mil judeus, quase o dobro do tamanho verificado em 1950.

Nem esse dinamismo econômico, no entanto, conseguiu compensar as forças dispersivas, de caráter demográfico e atitudinais, que a comunidade tem experimentado nas últimas décadas. Com o fim do ciclo migratório, São Paulo também registrou uma perda significativa a partir de 1980: os que se identificaram como judeus diminuíram de 41 mil em 1980 para menos de 39 mil em 1991. ${ }^{14}$

Porto Alegre, a terceira maior comunidade brasileira, por sua vez, continuou a crescer até 1980, mas estagnou desde então em algo próximo a 7 mil pessoas. No conjunto, as três maiores comunidades concentravam quase $83 \%$ de todos os judeus brasileiros em 1980, tendo esta percentagem decaído cerca de um ponto percentual no censo seguinte. Teriam os judeus brasileiros embarcado no processo de desconcentração metropolitana verificado no país a partir dos anos 80 (Martine, 1994)?

Independente de processamentos especiais, o censo de 1980 publicou os resultados da variável religião ao nível mais básico dos distritos, tornando assim possível uma análise do padrão de distribuição espacial dos judeus no interior da própria célula urbana. Como São Paulo abriga a maior concentração de judeus no país, este município foi escolhido para a análise neste nível geográfico.

Mesmo no interior do Município de São Paulo, judeus estão altamente concentrados, como revela a Tabela 6: apenas dez distritos da capital paulista eram responsáveis por mais de $80 \%$ de todos os judeus vivendo no município por ocasião do censo de 1980. Mais da metade deles estava concentrada em apenas quatro distritos. E só Santa Cecília abrigava mais de $17 \%$ de todo grupo. Com mais de 7 mil pessoas, Santa Cecília tinha em 1980 mais judeus que todo o Estado do Rio Grande do Sul. Em nenhum destes bairros, no entanto, judeus eram a maioria da população. Mesmo em Santa Cecília, judeus representavam pouco mais de 8\% da população local. Apenas o Bom Retiro, tradicional assentamento de judeus em São Paulo, exibia uma percentagem mais elevada: $21,4 \%$ do total.
Tabela 6

\section{Município de São Paulo - População Judaica e Total, por Distritos Selecionados, na Data do Censo de 1980}

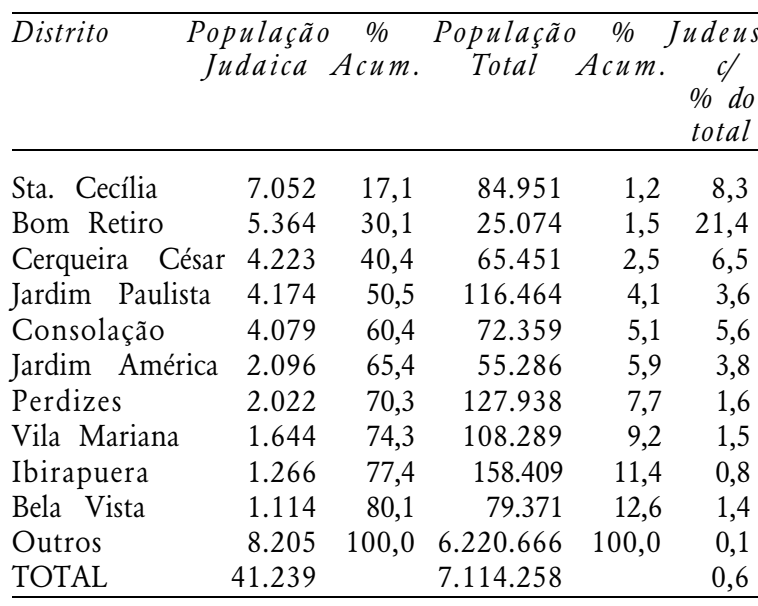

Fonte: IBGE, Censo demográfico de 1980, vol. 1, tomo 4, número 19 (São Paulo).

Os dados do censo de 1980 apenas confirmam um padrão comum a outros destinos de imigração judaica na América: a concentração na região central das metrópoles, em geral ao redor do centro financeiro e comercial (Taschner e Decol, 1992). Enquanto $80 \%$ dos judeus paulistanos viviam nos dez distritos listados na Tabela 6 por ocasião do censo de 1980, a mesma região reunia apenas 12,6\% da população total do município. Esta concentração no centro expandido da cidade pode ser melhor visualizada na Figura 1.

A metrópole paulista, por sua vez, experimentaria crescimento intenso na segunda metade do século XX, tendo chegado a 1996 com 16,6 milhões de habitantes. $\mathrm{Na}$ esteira deste intenso crescimento vieram os problemas urbanos: pobreza de grandes contingentes da população, marginalidade, violência, desequilíbrios ambientais e muitas outras atribulações típicas das megacidades do Terceiro Mundo. Neste contexto, setores afluentes da classe média têm reagido simplesmente deixando para trás os grandes centros metropolitanos. Como a distribuição de renda entre judeus tem uma configuração diferente da maioria da população brasileira, com participação bem mais significativa da classe média, é lícito imaginar que estejam envolvidos nestes fluxos de contra-urbani- 
Figura 1

Município de São Paulo -

Distritos com Maiores Concentrações de Judeus,

por Ocasião do Censo de 1980

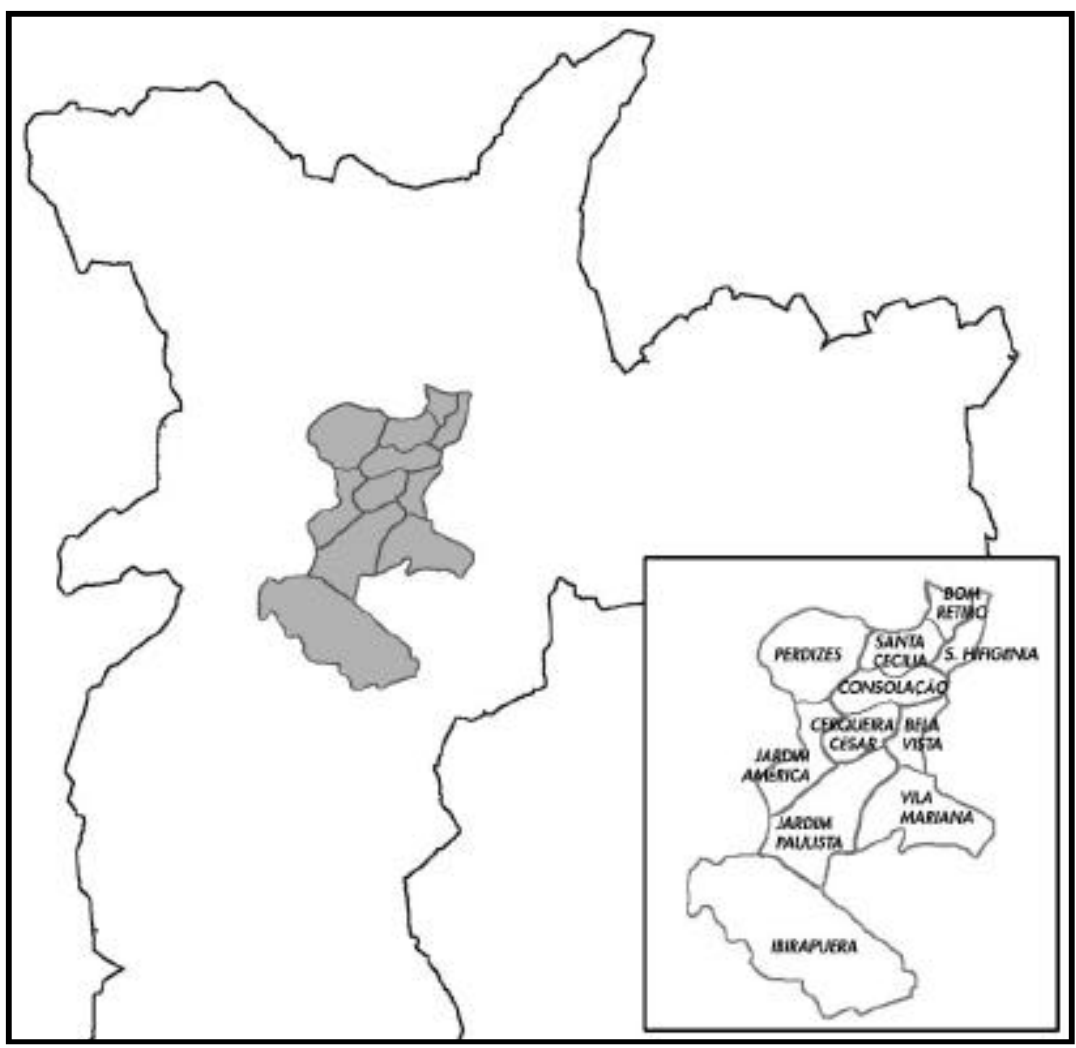

Fonte: IBGE, Censo demográfico de 1980, vol 1, tomo 4, número 19 (São Paulo).

zação (Martine, 1994) em proporção maior do que o conjunto da população.

O certo é que este movimento pode contribuir para aumentar ainda mais as perdas atitudinais, já que longe dos centros urbanos tornam-se mais escassas as oportunidades de cultivar a identidade judaica. A dispersão espacial, portanto, é mais um fator a aumentar ainda mais as dificuldades para que o grupo possa manter seu vigor demográfico e sua singularidade sem se dissolver completamente no caldeirão étnico brasileiro.

\section{Conclusão}

Os estudos sobre a minoria judaica no país têm crescido ultimamente, assim como as aborda- gens quantitativas. No caso de uma minoria cujos números são tão pequenos quando comparados à população brasileira em geral, uma visão quantitativa é um ponto de partida fundamental. No caso dos judeus, uma abordagem deste tipo é facilitada pelo fato de o grupo ter sido sistematicamente pesquisado como categoria da pergunta sobre religião nos censos demográficos do IBGE.

Dada a incerteza que cerca os dados relativos assim obtidos, qualquer conclusão deve ser relativizada e vista com cautela. Apesar disto, algumas conclusões parecem se impor, em consonância com resultados obtidos para outras comunidades judaicas da diáspora. Devido a taxas de fecundidade muito baixas, um número crescente de casamentos mistos, e ao complexo emaranhado de fatores 
que contribuem para uma erosão progressiva da identidade cultural em um contexto de secularização, judeus brasileiros estão enfrentando dificuldades cada vez maiores para manter seu contingente populacional. De fato, o número de pessoas que se identificaram como judeus diminuiu entre 1980 e 1991, provavelmente pela primeira vez desde que membros deste grupo começaram a imigrar em massa para o Brasil, a partir da década de 1920.

A se manter estas tendências, judeus poderão estar cada vez mais expostos às poderosas forças de assimilação e de secularização da sociedade brasileira. No limite, correm o risco de perder sua identidade como um grupo social específico, com uma história e uma cultura distintas.

Claro que estas tendências podem ser revertidas por um movimento de ordem cultural, que revalorize a identidade religiosa. Embora esta seja uma possibilidade, e embora se verifiquem processos de contra-secularização nas sociedades modernas e em modernização, como é o caso da brasileira, estes movimentos são posteriores ao período em estudo. Se este movimento já se fez sentir ao nível da dinâmica demográfica da comunidade judaica, é algo que só o censo do ano 2000 poderá revelar.

\section{NOTAS}

1 Importante frisar a ausência, nesta lista, de atributos raciais. Judeus podem ser tudo, menos uma raça (Shapiro, 1970).

2 Os dados provenientes da pergunta sobre religião dos censos têm sido pouco explorados em geral desde o desaparecimento de Cândido Procópio Ferreira de Camargo.

3 Faz parte da tradição censitária brasileira que categorias introduzidas em um levantamento permaneçam nos levantamentos posteriores para efeito de compatibilidade nas comparações.

4 O interior do Estado de São Paulo, onde vigorava a rede urbana do café, parece ter sido o máximo do rural a que se lançaram algumas famílias. Ainda assim, mesmo estes acabariam imigrando para a capital (Fausto, 1997).

5 A presença pouco expressiva dos judeus no então nascente proletariado industrial urbano é assunto complexo demais para ser tratado aqui. Para uma discussão sobre a estrutura ocupacional dos judeus na Europa do entre-guerras ver Mendelsohn (1983).

6 Questão judaica era a expressão tradicionalmente usada em referência ao "problema" da minoria judaica em diversos países da Europa Central no período do entreguerras. Para alguns, a presença dos judeus era um problema para o qual se deveria achar uma solução política, que muitas vezes era a emigração (Mendelsohn, 1983).

7 O termo ashkenazi, em hebraico, ou asquenaze (segundo o Aurélio) designava originalmente judeus de ascendência alemã. Como a maioria dos judeus dos países da Europa do Centro e do Leste eram descendentes de judeus franco-alemães, o termo veio a ser aplicado a judeus europeus em geral, em oposição a judeus sefaraditas, provenientes dos países islâmicos do Oriente Médio e Norte da África.

8 Diáspora é o termo comumente usado para referir-se às comunidades judaicas fora de Israel.

9 Nível de reposição é um conceito-chave em Demografia, definido como o nível de fertilidade de uma coorte de mulheres necessário para apenas "repô-las" e manter o tamanho da população estável. Em geral, aproximadamente 2,1 filhos por mulher.

10 A lista de países pesquisados pelo IBGE reflete o mapa político da Europa por ocasião da preparação dos trabalhos censitários.

11 Sefaradis (ou sefaraditas, segundo o Aurélio) é a denominação dada aos judeus de origem espanhola ou portuguesa que se espalharam pela África do Norte e pelo Império Otomano após sua expulsão da Península Ibérica no fim do século XV. Muitos permaneceram em países do Oriente Médio até que o aparecimento do Estado de Israel, em 1948, desse início a conflitos que acabariam resultando na sua expulsão (Millman, 1983).

12 Para uma discussão sobre os “sem religião” em pesquisas e censos, ver Glenn (1987).

13 Berger (1985) sugere que a secularização seja ainda mais intensa entre judeus do que entre outros grupos religiosos.

14 Importante lembrar que o censo de 1991 utilizou uma amostra menor do que o precedente, podendo, portanto, incorrer em erros amostrais maiores.

\section{BIBLIOGRAFIA}

ALVIM, Zuleika. (1998), "Imigrantes: a vida privada dos pobres do campo", in Nicolau Sevcenko (ed.), História da vida privada no Brasil, vol. 3, São Paulo, Companhia das Letras.

ANDERSON, Margo J. (1988), The American census a social history. New Haven/Londres, Yale University Press.

ARAÚJO, Maria de F. Infante. (1992), "Os cem últimos anos na história da cidade e a formação da Grande São Paulo”, in Fundação Seade, Cenários da urbanização paulista - a Região Administrativa de São Paulo, São Paulo, Fundação Seade, Coleção São Paulo no Limiar do Século XXI, n. 6, pp. 53-92. 
AVNI, Haim. (1992), Judios en América. Madri, Editorial Mapfre.

BARON, Salo. (1957), $A$ social and religious history of the jezes. $2^{\circ}$ ed., Nova York/Londres, Columbia University Press.

(1964), The Russian jere under tsars and soviets. Nova York, Macmillan.

BASSANEZI, Maria Silvia C. Beozzo. (1996), "Imigrações internacionais no Brasil, um panorama histórico", in Neide Patarra (org.), Emigração e imigração internacionais no Brasil contemporâneo, São Paulo, FNUAP/Nesur/NEPO.

BLACK, Edwin. (2001), A IBM e o Holocausto - a aliança estratégica entre a Alemanha nazista $e$ a mais poderosa empresa americana. Rio de Janeiro, Campus.

BERGER, Peter L. (1985), O dossel sagrado, elementos para uma sociologia da religião. São Paulo, Paulinas.

BLAY, Eva Alterman. (1997), "Judeus na Amazônia", in Bila Sorj (org.), Identidades judaicas no Brasil contemporâneo, Rio de Janeiro, Imago.

BODNAR, John. (1985), The transplanted: a history of immigrants in urban America. Bloomington, Indiana University Press.

CAMARGO, Cândido Procópio Ferreira de. (1984), “A categoria 'religião' em censos brasileiros”, in ABEP, Censos, consensos, contra-sensos, São Paulo, ABEP, pp. 215-22.

DECOL, René Daniel. (1999), Imigrações urbanas para o Brasil: o caso dos judeus. Tese de doutorado. Campinas, Universidade Estadual de Campinas.

ENGELMAN, Uriah Z. (1961), "Sources of Jewish statistics", in Louis Finkelstein (ed.), The jewes, their bistory, culture and religion, vol. 2, Londres, Peter Owen.

FAUSTO, Boris. (1991), Historiografia da imigração para São Paulo. São Paulo, Sumaré/FAPESP.

(1997), Negócios e ócios: bistórias da imigração. São Paulo, Companhia das Letras.

(1998), "Imigração, cortes e descontinuidades", in Lilia Moritz Schwarcz (ed.), História da vida privada no Brasil, vol. 4, São Paulo, Companhia das Letras.

FONSECA, Alexandre Brasil. (1998), "Nova era evangélica, confissão positiva, e o crescimento dos sem religião", in VIII Jornada sobre as Alternativas Religiosas na América Latina, São Paulo, digital.
GLENN, Norval D. (1987), “The trend in 'no religion' respondents to U.S. national surveys, late 1950s to early 1980s". Public Opinion Quarterly, 51, Fall: 293-314.

GRÜN, Roberto. (1999), "Construindo um lugar ao Sol: os judeus do Brasil”, in Boris Fausto (org.), Fazer a América - a imigração em massa para a América Latina, São Paulo, Edusp.

IBGE. Censos demográficos de 1940, 1950, 1960, 1980 e 1991. Vários volumes. Rio de Janeiro, IBGE.

KING, Gary, KEOHANE, Robert O. e VERBA, Sidney. (1994), Designing social inquiry - scientific inference in qualitative research. Princeton, New Jersey, Princeton University Press.

KLEIN, Herbert S. (1989), "A integração social e econômica dos imigrantes portugueses no Brasil no fim do século XIX e no século XX". Revista Brasileira de Estudos de Populaşão, 6, 2:17-37.

(1999), "Migração internacional na história das Américas", in Boris Fausto (org.), Fazer a América - a imigração em massa para a América Latina, São Paulo, Edusp.

LESSER, Jeffrey Howard. (1995), O Brasil e a questão judaica: imigraşão, diplomacia e preconceito. Rio de Janeiro, Imago.

LESTSCHINSKY, Jacob. (1961), "Jewish migrations, 1840-1956", in Louis Finkelstein (ed.), The jeres, their history, culture and religion, vol. 2, Londres, Peter Owen.

LEVINE, Robert M. (1995), "Research on Brazilian jewry: an overview". Canadian Journal of Latin American and Caribbean Studies, 20, 3940:227-37.

MARTINE, George. (1994), A redistribuição espacial da população brasileira durante a década de 80. Brasília, IPEA.

MENDELSOHN, Ezra. (1983), The jeres of East Central Europe between the World Wars. Bloomington, Indiana University Press.

MILLMAN, Ivor I. (1983), "Data on diaspora Jewish populations from official censuses", in P. Glikson, S.J. Gould e U.O. Schmelz (eds.), Studies in jewish demography - survey for 19721980, Jerusalém, Institute of Contemporary Jewry, The Hebrew University, pp. 31-120.

MORTARA, Giorgio. (1985), "Memories of a life-time", in A tribute to Giorgio Mortara, Roma, Università Degli Studi di Roma "La Sapienza", Facoltà di Sicenze Statistiche Demografiche e Attuariali, Dipartimento di Scienze Demografiche, pp. 61-94. 
MOYA, Jose C. (1998), Cousins and strangers Spanish immigrants in Buenos Aires, 1850 1930. Berkeley/Londres/Los Angeles, University of California Press.

PATARRA, Neide Lopes (org). (1996), Emigração $e$ imigração internacionais no Brasil contemporâneo. São Paulo, FNUAP/Nesur/NEPO.

PIERUCCI, Antônio Flávio. (1998), "Secularização em Max Weber: da contemporânea serventia de voltarmos a acessar aquele velho sentido". Revista Brasileira de Ciências Sociais, 37 (13): 43-73.

PIERUCCI, Antônio Flávio e PRANDI, Reginaldo. (1996), A realidade social das religiões no Brasil - religião, sociedade e política. São Paulo, Hucitec.

RATTNER, Henrique (org). (1972), Nos caminhos da diáspora. São Paulo, Centro Brasileiro de Estudos Judaicos/USP.

(1977), Tradição e mudança: a comunidade judaica em São Paulo. São Paulo, Ática.

ROBEY, Bryant. (1984), "The 1990 census: a view from 1984”. American Demographics, July: 2446.

ROWLAND, Richard H. (1986), “Geographical patterns of the jewish population in the pale of sattlement of late nineteenth century Russia”. Jewish Social Studies, Nova York, 48, 3-4, Summer-Fall: 207-34.

SCHMELZ, U.O. (1972), "Análise demográfica do judaísmo mundial”, in Henrique Rattner (org.), Nos caminhos da diáspora, São Paulo, Centro Brasileiro de Estudos Judaicos/USP.

(1981), "Jewish survival: the demographic factors”. American Jewish Year Book, Nova York, The American Jewish Committee, 81: 61-117.

(1983), "Evolution and projection of world jewish population”, in P. Glikson, S.J. Gould e U.O. Schmelz (eds.), Studies in jewish demography - survey for 1972-1980, Jerusalém, Institute of Contemporary Jewry, The Hebrew University.

SCHMELZ, U.O. e DELLAPERGOLA, Sergio. (1985), "The demography of Latin American jewry". American Jewish Year Book, Nova York, The American Jewish Committee, 85: 51-102.
(1992), "World jewish population, 1990”. American Jewish Year Book, Nova York, The American Jewish Committee, 92: 484-512.

SELTZER, William. (1998), "Population statistics, the Holocaust, and the Nuremberg Trials". Population and Development Review, 24, September: 511-52.

SHAPIRO, Harry L. (1970), "O povo da terra prometida”, in Juan Comas et al., Raça e ciência I, São Paulo, Perspectiva, pp. 111-88.

SORJ, Bila. (1997a), "Conversões e casamentos 'mistos': a produção de 'novos judeus' no Brasil”, in Bila Sorj (ed.), Identidades judaicas no Brasil contemporâneo, Rio de Janeiro, Imago.

(1997b), “'Normalizando’ o povo judeu: a experiência da Jewish Colonization Association no Brasil”, in Bila Sorj (ed.), Identidades judaicas no Brasil contemporâneo, Rio de Janeiro, Imago.

STILLMAN, Norman A. (1991), The jezes of Arab lands in modern times. Filadélfia/Nova York, The Jewish Publication Society of America.

TASCHNER, Suzana P. e DECOL, René D. (1992), População judaica no Brasil: um estudo demográfico - projeto de pesquisa. São Paulo, mimeo.

TRENTO, Angelo. (1989), Do outro lado do Atlântico: um século de imigração italiana no Brasil. São Paulo, Nobel.

TRUZZI, Oswaldo Mário Serra. (1997), Patrícios sírios e libaneses em São Paulo. São Paulo, Hucitec.

TUCCI CARNEIRO, Maria Luiza. (1988), O anti-semititsmo na era Vargas (1930-1945). São Paulo, Brasiliense.

(1996), Brasil, um refúgio nos trópicos a trajetória dos refugiados do nazi-fascismo. São Paulo, Estação Liberdade/Instituto Goethe.

WILSON, Bryan. (1985), "Secularization, the inherited model", in Philip E. Hammond (ed.), The sacred in a secular age: toward revision in the scientific study of religion, Berkeley, University of California Press.

WISCHNITZER, Mark. (1948), To dwell in safety: the story of jewish migration since 1800. Philadelphia, The Jewish Publication Society of America. 